\title{
REFLEXÃO SOBRE A FORMAÇÃO EM DUAS LÍNGUAS ESTRANGEIRAS (INGLÊS E UMA OUTRA LÍNGUA) PELAS UNIVERSIDADES CHINESAS E PROPOSTA DA DISCIPLINA DE TRADUÇÃO INGLÊS - PORTUGUÊS PARA OS LICENCIANDOS EM PORTUGUÊS
}

\author{
Zhihua $\mathrm{Hu}^{1,2^{*}}$ \\ ${ }^{1}$ Zhejiang International Studies University, China \\ ${ }^{2}$ Universidade de Aveiro, Portugal \\ Maria Teresa Roberto ${ }^{2 \star x}$ \\ ${ }^{2}$ Universidade de Aveiro, Portugal
}

\begin{abstract}
Resumo
A formação em duas línguas estrangeiras (geralmente inglês e uma outra língua estrangeira) pelas instituições chinesas pode remontar à década 80 (Sun, 2015:91). Apesar disso, existem ainda algumas insuficiências, tais como, a falta de materiais adequados, e de disciplinas que integram conhecimentos de duas línguas, por exemplo, disciplinas sobre a comparação, o contraste e a possível tradução entre as duas línguas estrangeiras. Sem disciplinas assim, os alunos só podem estudar as duas línguas separadamente; o que não só aumenta a tarefa dos alunos, mas também não é favorável para ativar a transferência positiva (Wang, 2012; $\mathrm{Li}, 2012$ ) do conhecimento em inglês na aprendizagem da segunda língua estrangeira. Além de apresentarmos e discutirmos a formação em duas línguas estrangeiras nas instituições chinesas, também propomos uma disciplina de tradução inglês - português para os licenciandos chineses em português. Como sustentação, as nossas considerações têm como base a discussão sobre a formação em duas línguas estrangeiras.

Palavras-chave: Licenciatura em Duas Línguas Estrangeiras; Licenciatura de Línguas Estrangeiras; Instituições Chinesas; Transferência Positiva e Negativa; Comparação, Contraste e Tradução entre Línguas Estrangeiras
\end{abstract}

\footnotetext{
" Doutor em Tradução e Terminologia pela Universidade de Aveiro e a Universidade Nova de Lisboa; investigador do Centro de Línguas, Literaturas e Culturas (CLLC) da Universidade de Aveiro; docente na Faculdade de Línguas e Culturas Ocidentais da Zhejiang International Studies University (China). Email: ramonhu@outlook. com, zhihua.hu@ua.pt, https://orcid.org/0000-0002-2235-8877.

** Docente no Departamento de Línguas e Culturas, da Universidade de Aveiro. Dirige o Programa Doutoral de Tradução e Terminologia; uma parceria da Universidade de Aveiro com a Universidade Nova de Lisboa. Atualmente, é coordenadora da Linha de Investigação em Tradução e Terminologia, do Centro de Línguas, Literaturas e Culturas. Email: mariateresaroberto@ua.pt, https://orcid.org/0000-0001-8973-7129
} 


\title{
REFLECTION ON TRAINING OF TWO FOREIGN LANGUAGES (ENGLISH AND ANOTHER LANGUAGE) BY CHINESE \\ UNIVERSITIES AND PROPOSAL OF ENGLISH - PORTUGUESE TRANSLATION DISCIPLINE FOR BACHELOR STUDENTS OF PORTUGUESE LANGUAGE
}

\begin{abstract}
The training of two foreign languages (usually English and another foreign language) by the Chinese universities can date back to the 1980s (Sun, 2015:91). Nevertheless, there are still some parts which need to be improved, such as the lack of adequate materials, and the insufficiency of disciplines linking knowledge of two foreign languages, for example, the disciplines on comparison, contrast and possible translation between the two foreign languages. Without such disciplines, students can only study the two languages separately, which not only increases the student's task, but also is not conducive to activating the positive transfer (Wang, 2012; $\mathrm{Li}, 2012$ ) of English knowledge in learning a second foreign language. In addition to presenting and discussing the training of two foreign languages by the Chinese institutions, in this work, we also want to propose an English - Portuguese translation discipline for Chinese bachelor students of Portuguese. In support of this, our considerations are based on the discussion of training of two foreign languages.

Keywords: Bachelor in Two Foreign Languages; Bachelor in Foreign Languages; Chinese Universities; Positive and Negative Transfer; Comparison, Contrast and translation between foreign Languages
\end{abstract}




\section{Introdução:}

Em relação à formação em duas línguas estrangeiras, para Sun (2015:91), as tentativas pelas universidades chinesas nesta área remontam à década oitenta: a Universidade de Estudos Internacionais de $\mathrm{Xangai}^{1}$ foi a primeira a abrir o curso em duas línguas estrangeiras (o inglês e o espanhol); posteriormente, em 2011, a mesma universidade começou a pôr em prática o plano de formação de talentos multilíngues em jornalismo, conforme o qual são selecionados alunos em jornalismo para estudar uma segunda língua estrangeira (francês, alemão e japonês) além do inglês; ou alunos em russo (alemão, francês, espanhol, árabe e japonês) para estudar, além do inglês, também o jornalismo². Através deste programa de graduação, pretende-se formar talentos que saibam duas línguas estrangeiras $^{3}$ (inglês e uma outra língua estrangeira) e, ao mesmo tempo, possuam conhecimentos sólidos na área de jornalismo.

De acordo com Sun (2015:91), na Universidade de Línguas Estrangeiras de Pequim ${ }^{4}$ também se iniciou um curso de duas línguas estrangeiras (o inglês e o francês) em 1984, e a partir de 2007, começaram a oferecer cursos de mestrado de interpretação simultânea (chinês, inglês, uma outra língua estrangeira).

Além destas duas universidades de línguas estrangeiras, existem outras (orientadas ao ensino de línguas estrangeiras ou não) a oferecer cursos semelhantes: tais como a Universidade de Línguas Estrangeiras de Dalian (licenciatura de formação em inglês e japonês ${ }^{5}$ ) e a Universidade Normal de Yunnan (licenciatura de formação em inglês e tailandês, inglês e vietnamita, e inglês e birmanês $\left.{ }^{6}\right)^{7}$ Apesar do desenvolvimento rápido da formação em duas línguas estrangeiras, Sun (2015:91) aponta que ainda não existe um documento diretriz que orienta essa formação, e que cada universidade tem o seu próprio modelo.

Com base na nossa pesquisa, em termos gerais, a formação universitária chinesa em línguas estrangeiras pode dividir-se nas seguintes categorias:
a. curso superior de línguas estrangeiras ( 3 anos)
b. licenciatura de línguas estrangeiras ( $4-5$ anos)
c. mestrado acadêmico de línguas estrangeiras ( 3 anos)
d. mestrado profissionalizante de línguas estrangeiras (2 anos)
e. doutoramento de línguas estrangeiras (3 - 4 anos)

Ao discutirmos a formação em duas línguas estrangeiras, nos referimos à licenciatura e mestrado de línguas estrangeiras, visto que só nestes dois programas se oferece a formação em duas línguas estrangeiras. Vejamos as subdivisões mais detalhadas:

- Licenciatura de línguas estrangeiras:

1) Licenciatura de formação em uma língua estrangeira (4 anos)

a) licenciatura de inglês

b) licenciatura de outras línguas estrangeiras ${ }^{8}$ 
De acordo com o documento de orientação "Opiniões sobre a Reforma do Ensino de Licenciatura em Línguas Estrangeiras para o Século XXI» (1998:4) do Comitê Consultivo para Especialidades de Línguas Estrangeiras do Ensino Superior (subordinado ao Ministério de Educação da China), deve-se incentivar os alunos em línguas estrangeiras, além de dominar os conhecimentos linguísticos da sua especialidade, a aprenderem uma segunda língua estrangeira. Isso quer dizer que para os alunos em inglês, eles devem aprender uma segunda língua estrangeira; e para os alunos em outras línguas estrangeiras, eles devem reforçar o aprendizado da língua inglesa. De acordo com a nossa pesquisa, as práticas concretas (embora possam ser diferentes conforme as universidades), geralmente, são o seguinte:

Se os alunos são da licenciatura de inglês, eles escolhem e aprendem uma segunda língua estrangeira (na maioria dos casos, são francês, alemão, russo, japonês e espanhol ${ }^{9}$ ) no segundo e terceiro ano da licenciatura (geralmente, 4 horas curriculares por semana; o número total é, geralmente, 64 horas escolares).

Se os alunos são da licenciatura de outras línguas estrangeiras, eles estudam o inglês, geralmente, também no segundo e terceiro ano da licenciatura (4 horas curriculares por semana; o adiamento do estudo de inglês resulta da consideração, pelas instituições, de que o estudo do inglês pode exercer transferência negativa no início da aprendizagem da segunda língua estrangeira). A licenciatura de português pertence a esta categoria embora os alunos estudem o inglês, as horas curriculares são poucas, visto que a ênfase está no estudo de português, e não no de inglês.

2) Licenciatura de formação em duas línguas estrangeiras (4 - 5 anos)

a) licenciatura de inglês + outra língua estrangeira (o ensino do inglês é a disciplina principal, mas entre as horas curriculares distribuídas para o inglês e para a outra língua estrangeira não existe grande diferença).

b) licenciatura de outra língua estrangeira + inglês (o ensino de outra língua estrangeira é principal, mas entre as horas curriculares distribuídas para a outra língua estrangeira e para o inglês não existe grande diferença).

c) licenciatura em duas línguas estrangeiras (com exceção do inglês, existem poucos casos de acordo com a nossa pesquisa; por exemplo, os alunos da licenciatura em ucraniano da Universidade de Línguas Estrangeiras de Pequim aprendem, ao mesmo tempo, também o russo, dada influência russa na cultura e economia da Ucrânia).

- Mestrado de línguas estrangeiras (2 - 3 anos $)^{10}$

a) mestrado de formação em uma língua estrangeira (na vertente de linguística, literatura, tradução, etc.).

b) mestrado de formação em duas línguas estrangeiras (na vertente de tradução, mais especificamente na área de interpretação, veja isso nas discussões mais detalhadas que desenvolvemos adiante).

No presente trabalho, pretendemos delinear a formação em duas línguas estrangeiras (inglês e outra língua estrangeira) pelas instituições chinesas e propor a criação de uma disciplina de tradução inglês - português para 
os licenciandos chineses em português (como língua estrangeira), visando integrar os conhecimentos linguísticos entre o inglês e o português e ativando a transferência positiva do inglês na aprendizagem do português.

\section{O modelo de formação em duas línguas estrangeiras:}

Quanto ao modelo de formação interdisciplinar nas instituições chinesas, de acordo com Mou (2015:53), este modelo, basicamente, divide-se em três tipos:

(1). língua estrangeira + conhecimentos da literatura, linguística, tradução, entre outras:

Os alunos aprendem a língua nos primeiros dois anos da licenciatura, e no terceiro e quarto ano da licenciatura, começam a estudar a literatura, a linguística, a tradução, entre outras.

(2). língua A + língua B (duas línguas estrangeiras):

Esta combinação pode ser a língua inglesa mais qualquer outra língua estrangeira, por exemplo, o inglês e o francês, o inglês e o alemão, o inglês e o japonês, entre outras.

(3). cursos não linguísticos (finanças, comércio, jornalismo) + língua estrangeira:

Os alunos, depois de acabar o curso, além de possuírem conhecimentos específicos das áreas profissionalizantes, dominam também uma língua estrangeira (geralmente, é a língua inglesa). As possíveis combinações podem ser jornalismo + inglês, finanças + inglês, comércio + inglês, diplomacia + inglês, entre outras.

É nosso objetivo retratar a formação em duas línguas estrangeiras (inglês e outra língua estrangeira) pelas instituições chinesas, por isso, iremos só considerar o segundo tipo de formação interdisciplinar, ou seja, a formação que inclua duas línguas estrangeiras.

\subsection{A situação atual da formação em duas línguas estrangeiras nas universidades chinesas}

\subsubsection{No nível de licenciatura:}

Nas universidades chinesas, os alunos de licenciatura em inglês precisam escolher e aprender uma segunda língua estrangeira (Comitê Consultivo para Especialidades de Línguas Estrangeiras do Ensino Superior, 1998:4). Geralmente, este aprendizado dura dois anos e começa no segundo ano da licenciatura; de acordo com a nossa pesquisa, esta segunda língua estrangeira pode ser francês, alemão, russo, espanhol, japonês, entre outras.

Na perspectiva de Ma \& Chen (2019:85), à exceção dos alunos que querem prosseguir o estudo de mestrado (no exame de admissão para o mestrado de inglês, os alunos têm que fazer a prova de segunda língua estrangeira), a maioria dos licenciados, depois de acabar o curso, esquece rapidamente esta segunda língua caso não a pratiquem. 
Isso, na opinião de Ma \& Chen (2019:85), não é o que é pretendido na formação oferecida na licenciatura em duas línguas estrangeiras; de acordo com os autores, os graduados da licenciatura em duas línguas estrangeiras devem ter uma base sólida nas duas línguas estrangeiras e possuir uma visão internacional analítica dos problemas.

A nosso ver, o que Ma \& Chen (2019) indicam realmente pode refletir a situação atual do ensino da segunda língua estrangeira para os licenciandos de inglês: os alunos escolhem e aprendem uma segunda língua estrangeira durante dois anos (segundo e terceiro ano da licenciatura). Mas como as horas curriculares são poucas para os alunos dominarem conhecimentos básicos desta segunda língua estrangeira, tornem-se difícil para eles, depois de acabar a licenciatura, usarem esta segunda língua estrangeira no trabalho (quando não são usados, estes conhecimentos muito rudimentares caem no esquecimento).

Como referimos acima, para Ma \& Chen (2019), este resultado não é o que se pretende na formação da licenciatura em duas línguas estrangeiras. Então, isto leva-nos a perguntar: O que é que pretende a formação da licenciatura em duas línguas estrangeiras? E o que é que pretende a formação de segunda língua estrangeira para os licenciandos de inglês?

No que diz respeito à formação na segunda língua estrangeira para os licenciandos de inglês, todos eles devem escolher e aprender uma segunda língua estrangeira; embora seja uma disciplina de caráter opcional, trata-se de uma opção obrigatória (ou seja, todos os licenciandos de inglês têm que escolher esta disciplina opcional). Isso também é refletido nos exames de admissão para o mestrado; ou seja, se os licenciandos de inglês querem prosseguir os estudos em mestrado, devem fazer a prova de segunda língua estrangeira. Depois de começar a frequentar o curso de mestrado, eles ainda precisam continuar a aprendizagem desta segunda língua estrangeira. De fato, através da formação em segunda língua estrangeira aos licenciandos de inglês, as universidades pretendem que os alunos tenham uma capacidade básica e prática para usar esta segunda língua estrangeira (os alunos só precisam ter os conhecimentos básicos da segunda língua estrangeira); ao passo que a licenciatura em duas línguas estrangeiras tem como objetivo formar talentos que dominam de maneira sólida os conhecimentos linguísticos de duas línguas estrangeiras.

São dois objetivos diferentes; por exemplo, na licenciatura em duas línguas estrangeiras (inglês ejaponês), oferecida pela Universidade de Línguas Estrangeiras de Dalian ${ }^{11}$, estabelece-se ainda as exigências específicas quanto ao domínio do inglês e o do japonês ${ }^{12}$ dos alunos quando estes acabam a licenciatura. Trata-se de exigências concretas, que se representam nos aspetos fonéticos, lexicais, de sintaxe, de análise textual, e nas quatro capacidades essenciais na aprendizagem de línguas estrangeiras: audição, fala, compreensão e escrita.

São exigências diferentes: para os licenciandos em inglês, o domínio da segunda língua estrangeira precisa ser básico; no entanto, para os alunos da licenciatura em duas línguas estrangeiras, as exigências são maiores. Isso talvez também possa explicar a razão pela qual a licenciatura em duas línguas (inglês e 
japonês) da Universidade de Línguas Estrangeiras de Dalian tem uma duração de 5 anos, visto que, geralmente, as licenciaturas na China duram só 4 anos.

Além disso, pela organização das unidades curriculares, também podemos observar as ênfases diferentes nestes dois tipos de formação. Podemos ver a seguinte organização das unidades curriculares pela Universidade de Línguas Estrangeiras de Dalian em relação a dois tipos de formação:

A formação em segunda língua estrangeira aos licenciandos em inglês (na vertente de tradução):

As disciplinas obrigatórias e opcionais em inglês: 1937 horas curriculares (sendo as obrigatórias de 1405 e as opcionais de 532; distribuídas entre 8 semestres, no total 4 anos) $)^{13}$

As disciplinas opcionais em segunda língua estrangeira (por exemplo, o japonês): 260 horas curriculares (distribuídas entre 4 semestres, totalizando 2 anos, incluindo o estudo dos conhecimentos básicos desta segunda língua estrangeira). ${ }^{14}$

A formação da licenciatura em duas línguas estrangeiras (o inglês como especialidade e o japonês como a outra língua estrangeira):

As disciplinas obrigatórias em inglês: 1881 horas curriculares (distribuídas entre 10 semestres, totalizando 5 anos $)^{15}$

As disciplinas obrigatórias em japonês: 1426 horas curriculares (distribuídas entre 10 semestres, totalizando 5 anos). A aprendizagem da língua inclui: o japonês nível básico; o japonês nível avançado; a compreensão oral; a conversação; a introdução da cultura e sociedade do Japão; a tradução do japonês para o chinês; a tradução do chinês para o japonês; a interpretação simultânea; a escrita; a gramática; a história do japonês). ${ }^{16}$

A comparação entre a organização das disciplinas das duas formações revela uma ênfase diferente: na formação de segunda língua estrangeira aos licenciandos em inglês, enfatiza-se mais o ensino da língua inglesa; ao passo que na formação da licenciatura em duas línguas estrangeiras, põe-se destaque no ensino de duas línguas estrangeiras (o inglês e uma outra língua estrangeira, no caso aqui exemplificado, o japonês).

\subsubsection{No nível de mestrado:}

A Universidade de Línguas Estrangeiras de Pequim ${ }^{17}$ começou a oferecer, a partir de 2007, o curso de mestrado em interpretação simultânea (entre o chinês, o inglês e uma outra língua estrangeira), ${ }^{18}$ com duração de dois anos.

Os alunos que frequentam este curso de mestrado vêm das licenciaturas de línguas estrangeiras (com exceção da língua inglesa); depois do treinamento intensivo de interpretação simultânea durante dois anos, quando acabam o curso, possuem a capacidade de interpretar entre o chinês, o inglês e uma língua estrangeira. Por enquanto, este mestrado de interpretação simultânea abarca oito línguas estrangeiras (com exceção ao inglês): alemão, francês, russo, espanhol, coreano, árabe, japonês e tailandês. Ou seja, os alunos vindos das licenciaturas destas oito línguas estariam aptos a frequentar este curso de mestrado. 
Além dos alunos chineses, este curso também admite alunos de outros países. Até o presente momento, houve alunos alemães, russos, espanhóis, etc. a frequentar este curso. ${ }^{19}$ Conforme o plano curricular deste curso de mestrado, os alunos admitidos estudam a interpretação e tradução entre o chinês e o inglês durante dois anos, entre o chinês e a outra língua estrangeira durante um ano. ${ }^{20}$ De acordo com o plano curricular, os alunos têm disciplinas obrigatórias relacionadas com a tradução e interpretação entre o chinês e o inglês no primeiro e segundo ano. Concretamente, as disciplinas incluem os seguintes aspetos: a tradução, a tradução audiovisual, a interpretação consecutiva e a interpretação simultânea. Só a partir do segundo ano os alunos têm disciplinas de tradução e interpretação entre o chinês e a outra língua estrangeira. ${ }^{21}$

Pelo que se nota, a ênfase é colocada sempre no treinamento da capacidade de tradução e interpretação entre o chinês e o inglês. Isso é bem refletido nas disciplinas que fazem parte do plano curricular: tradução entre chinês e inglês, tradução audiovisual entre chinês e inglês, e interpretação consecutiva e simultânea entre chinês e inglês. No total, são 36 créditos atribuídos ao desenvolvimento de competências em tradução e interpretação entre o chinês e o inglês.

Como já mencionámos acima, os alunos só começam a ter aulas de tradução e interpretação entre o chinês e a outra língua estrangeira no segundo ano de mestrado. $\mathrm{O}$ número de créditos atribuídos ao treinamento de tradução e interpretação entre o chinês e essa outra língua estrangeira são em número menor: 8 créditos. Ressalta-se aqui que, para concluir o mestrado, os alunos devem completar 52 créditos.

Pelas percentagens de créditos distribuídos para o treinamento de tradução e interpretação entre chinês e inglês, e entre chinês e outra língua estrangeira, observa-se que o destaque fica sempre no primeiro tipo de treinamento; ou seja, a ênfase desta formação tem como objetivo principal exercitar a capacidade de tradução e interpretação entre o chinês e o inglês.

Assim sendo, questionamos se esta organização de unidades curriculares e distribuição de créditos consegue garantir que os graduados possam realmente dedicar-se às atividades de tradução e interpretação entre chinês, inglês e a outra língua estrangeira. As nossas dúvidas derivam dos seguintes aspetos:

1. as unidades curriculares e créditos distribuídos para o treinamento de tradução e interpretação entre o chinês e a outra língua estrangeira são em número bem menor do que os destinados ao treinamento de tradução e interpretação entre o chinês e o inglês.

2. pelo que se nota, não existem disciplinas que visam ligar as duas línguas estrangeiras (o inglês e a outra língua estrangeira); ou seja, não se encontram disciplinas de tradução ou interpretação entre o inglês e a outra língua estrangeira. Se isso é o fato, como podemos imaginar que os graduados são capazes de interpretar entre o chinês, o inglês e uma outra língua estrangeira? Pelos treinamentos acima referidos, podemos supor que os graduados deste 
curso podem fazer a tradução e interpretação entre o chinês e o inglês e o chinês e a outra língua.

A nosso ver, no que diz respeito ao treinamento e fortalecimento da capacidade de traduzir e interpretar entre o inglês e a outra língua estrangeira, ainda há um caminho longo a percorrer, uma vez que todos os alunos deste mestrado, durante sua licenciatura em alemão, francês, russo, espanhol, coreano, árabe, japonês ou tailandês, já tiveram disciplinas de tradução e interpretação entre o chinês e a língua estrangeira; para os alunos integrados neste mestrado, o que eles realmente precisam, além dos treinamentos acima mencionados, é o treinamento e fortalecimento da capacidade de traduzir e interpretar entre o inglês e a outra língua estrangeira.

A nosso ver, há dois motivos para a ausência de disciplinas de tradução e interpretação entre o inglês e a outra língua estrangeira:

1. A falta de professores qualificados para lecionar disciplinas que integrem as duas línguas estrangeiras (tais como disciplinas de tradução e interpretação entre as duas línguas estrangeiras, e as relacionadas com o estudo comparativo e contrastivo entre as duas línguas estrangeiras, entre outras);

2. A falta de materiais adequados que possam relacionar o estudo entre duas línguas (mesmo que os alunos dominem bem ambas as línguas estrangeiras, não conseguem interligar os conhecimentos linguísticos entre essas duas línguas).

$\mathrm{Na}$ realidade, em comparação com o primeiro motivo, o segundo parece mais fácil de ser resolvido. Para o segundo motivo, pode recomendar-se aos alunos a leitura de materiais escritos em inglês sobre a aprendizagem das outras línguas estrangeiras, por exemplo, a gramática escrita em inglês sobre a outra língua estrangeira. Os alunos integrados neste mestrado, através da leitura deste tipo de materiais, por um lado, podem rever os conhecimentos linguísticos já adquiridos; por outro lado, também podem mobilizar ideias básicas sobre a relação correspondente de estruturas gramaticais e lexicais entre o inglês e a outra língua estrangeira. Para tornar isso mais viável e eficaz, os professores podem ajudar os alunos a sintetizar e resumir as relações correspondentes nos aspetos gramatical e lexical entre as duas línguas.

Estamos muito conscientes de que, com práticas assim, é mais fácil que os alunos caiam na armadilha "estruturalista" da tradução, pensando que a tradução entre duas línguas estrangeiras não passa de mera substituição dos elementos gramaticais e lexicais de uma língua por outra, apesar de, na prática tradutiva real, a tradução ser muito mais do que isso. Em nossa opinião, esta síntese e resumo das relações gramaticais e lexicais correspondentes podem ser feitos apenas no início da aprendizagem, com vista a ajudar os alunos a estabelecer a ideia de "correspondência" entre duas línguas estrangeiras; quando os alunos 
possuírem conhecimentos sólidos de correspondência entre as duas línguas, os professores podem enfatizar outros elementos acima do nível lexical e gramatical, tal como, em nível textual. Para os alunos deste curso, é importante estabelecer as relações de correspondência entre o inglês e a outra língua estrangeira, visto que, quando estavam na licenciatura, não tinham disciplinas assim; ou seja, para os alunos, estes conhecimentos interlinguísticos (as duas línguas estrangeiras) são adquiridos no seu início do mestrado, numa estratégia metalinguística que os mestrandos já são capazes de implementar, por força da sua maturidade de aprendizagem e dos conhecimentos que possuem em relação às línguas.

\subsection{Os problemas existentes:}

$\mathrm{Na}$ nossa apresentação da situação atual da formação em duas línguas estrangeiras pelas instituições chinesas, abordamos alguns aspetos que, a nosso ver, precisam ser melhorados. Nesta parte, iremos aprofundar alguns desses aspetos.

Para Huang (2017:79), os problemas existentes relacionados à formação em duas línguas estrangeiras representam-se nos seguintes aspetos:

(1). O desenvolvimento da formação em duas línguas estrangeiras (o inglês e outra língua estrangeira):

Quanto ao desenvolvimento da formação em duas línguas estrangeiras, as instituições devem considerar os seguintes fatores: conjuntura econômica e comercial do mundo, o desenvolvimento social, as necessidades das iniciativas e políticas nacionais, as características locais. Por exemplo, sob a iniciativa de cooperação econômica internacional "Uma Faixa, Uma Rota ${ }^{22}$ " do governo chinês, tem havido uma procura cada vez maior de profissionais que saibam as línguas dos países abrangidos por esta iniciativa; para satisfazer essa necessidade, muitas universidades chinesas começaram a oferecer licenciaturas nas línguas desses países.

Na opinião de Huang (2017:78), as universidades chinesas, onde se oferecem licenciaturas em duas línguas estrangeiras (o inglês e a outra língua estrangeira), dividem-se em dois tipos: as universidades orientadas para o ensino de línguas estrangeiras e as universidades incentivadas pelas políticas nacionais.

Quanto ao primeiro tipo, ou seja, as universidades orientadas para o ensino de línguas estrangeiras, como a sua classificação indica, sabemos que são instituições focadas tradicionalmente no ensino de línguas estrangeiras. Estas universidades costumam ser as mais sensíveis às políticas e iniciativas governamentais; ou seja, o aumento de cursos de línguas estrangeiras por estas universidades está relacionado com as políticas promovidas pelo governo em relação aos outros países. Aqui indicamos só o "aumento de cursos", tendo em vista que raramente acontece uma redução de cursos nestas universidades. Se existir mais oferta do que procura no mercado laboral, certos cursos não serão abertos anualmente; por exemplo, para recuperar o equilíbrio entre a procura e a oferta, para certos cursos, a Universidade de Línguas Estrangeiras de Pequim 
(com 101 licenciaturas de línguas estrangeiras até ao ano de 2019²3) só admite alunos de quatro em quatro anos.

No que diz respeito ao segundo tipo, são universidades não orientadas para o ensino de línguas estrangeiras, que seguem as iniciativas governamentais para abrir cursos de línguas estrangeiras. As universidades do segundo tipo, geralmente, são as que se situam nas províncias fronteiriças. Com a ajuda das suas posições privilegiadas, estas universidades, apesar de não se focarem no ensino de línguas estrangeiras, oferecem também cursos de línguas estrangeiras (as línguas praticadas nos países com os quais se limitam estas províncias). Por exemplo, sob a iniciativa de cooperação econômica internacional de "Uma Faixa, Uma Rota" pelo governo chinês, a Universidade Normal de Yunnan abriu os cursos de licenciatura de vietnamita, birmanês e tailandês (Huang, 2017:78). A província de Yunnan fica no sudoeste da China, fazendo fronteira com três países: Vietnam, Laos e Camboja, e próxima à Tailândia; o que poderia vir a ser uma possível explicação para a implementação destes cursos nesta universidade.

\section{(2). Quanto à construção de grupos de docentes:}

De acordo com Huang (2017:79), a formação em duas línguas estrangeiras (inglês e uma outra língua estrangeira) está ainda em fase de experimentação e não existem muitos professores experientes no ensino de duas línguas estrangeiras. Por esse motivo, na opinião de Huang (2017:79), a formação em duas línguas estrangeiras pode ter a seguinte organização: quando os alunos aprendem inglês, são um grupo de professores que ministram as aulas e quando os alunos aprendem outra língua estrangeira, são outro grupo de professores.

Na explicação de Huang (2017), esta organização tem duas vantagens:

a. os professores são especializados na sua própria área (numa certa língua estrangeira), por isso, a qualidade do ensino é garantida;

b. com esta organização, a curto prazo, a falta de professores qualificados no ensino de duas línguas estrangeiras pode ser resolvida.

Admitimos o mérito das recomendações de Huang; no entanto, em nossa opinião, o que ele sugere não apresenta muita aplicabilidade no que diz respeito à melhoria da formação em duas línguas estrangeiras, visto que o que ele propõe são as práticas vigentes e frequentes pelas instituições chinesas em relação à formação em duas línguas estrangeiras. A desvantagem dessa organização de recursos docentes é muito evidente: os alunos parecem frequentar duas licenciaturas (o inglês e uma outra língua estrangeira), e um possível resultado seria um domínio ineficiente do inglês e da outra língua estrangeira por parte dos alunos, dado que aprendem as duas línguas separadamente e não sabem como aliar os conhecimentos linguísticos das duas línguas de forma sinérgica. Quando aqui usamos a palavra "aliar", queremos dizer a implementação da comparação e contraste entre estas duas línguas estrangeiras. 
Muitos alunos (de acordo com nossa experiência como professores), no processo de aprendizagem destas duas línguas, comparam e contrastam as estruturas gramaticais e lexicais consciente ou subconscientemente. Na realidade, pela nossa experiência, quando os alunos chineses iniciam a aprendizagem da primeira língua estrangeira (geralmente, o inglês) ${ }^{24}$ costumam também comparar e contrastar esta língua com a sua língua maternal; claro, isso, muitas vezes, também está relacionado com a maneira como os professores chineses ministram as aulas, visto que, geralmente, os professores explicam os conhecimentos de inglês em chinês; o que, inevitavelmente, leva os alunos a adquirirem o hábito de comparar e contrastar as duas línguas. Trata-se de um hábito que exerce forte influência na aprendizagem das línguas estrangeiras: primeiro comparam e contrastam a língua materna como o inglês, depois comparam e contrastam o inglês com a outra língua estrangeira. Após a comparação e contraste dos elementos gramaticais e lexicais entre as duas línguas, os alunos podem identificar algumas "regras" para depois pôr em prática no seu estudo. Se o resultado deste "pôr em prática" é positivo, trata-se de uma "regra" bem-sucedida; se é negativo, é uma "regra" fracassada. Como são conclusões tiradas pelos próprios alunos e devido à falta de conhecimentos linguísticos por parte dos alunos, as regras concluídas podem ser percepções subjetivas dos alunos.

Para melhor resolver este problema, os professores poderiam considerar a criação de disciplinas de "comparação e contraste entre o inglês e a outra língua estrangeira" ou "tradução entre o inglês e essa outra língua".

Para os professores de línguas estrangeiras (com exceção do inglês), o primeiro tipo de disciplinas revela-se mais viável (as disciplinas de comparação e contraste entre o inglês e a outra língua estrangeira), tendo em conta que os professores são especialistas nas suas próprias áreas (numa determinada língua estrangeira) e a maior parte destes sabe o inglês (a maioria parte dos alunos chineses estudam inglês na escola secundária e fazem prova de inglês no exame de admissão para a Universidade), logo, não é difícil para eles prepararem conteúdos relacionadas com a comparação e contraste entre o inglês e a língua que ensinam.

No mercado chinês, com relação às principais línguas estrangeiras, existem obras que abordam a comparação entre inglês e a outra língua estrangeira, apesar da quantidade ser ainda limitada, por exemplo:

a) Gramática do Francês: Comparação entre o Francês e o Inglês (Gao Weiwan \& Gai Feihong, 2011, Higher Education Press)

b) Gramática Contrastiva entre o Alemão e o Inglês (Li Dongliang, 1993, Hubei Science \& Technology Press)

c) A Comparação e Tradução entre o Japonês e o Inglês (Nível Elementar) (Gu Yongqing, 2006, Henan People’s Publishing House)

Além das obras relacionadas com a comparação e contraste entre o inglês e a outra língua estrangeira, os dicionários bilíngues (entre o inglês e a outra língua estrangeira) também foram introduzidos no mercado chinês há muitos anos.

Em 2001, a série de dicionários de bolso entre o inglês e uma outra língua estrangeira (alemão, russo, francês, português, espanhol, grego e italiano) da 
Editora Harper Collins (sediada em Nova Iorque) foi introduzida pela Shanghai Language Education Press no mercado chinês. ${ }^{25}$ Pela popularidade alcançada no mercado chinês, em 2006, a série de Collins Dicitionary \& Grammar (entre o inglês e uma outra língua estrangeira, a saber, alemão, francês, espanhol e italiano) foi introduzida pela mesma editora chinesa, que integra não só as entradas mais frequentes, mas também as que estão relacionadas com áreas mais específicas (negócios, informática, turismo, entre outras). Além disso, nesta série de dicionários bilíngues ficam também anexadas explicações gramaticais desta língua estrangeira - são explicações escritas em inglês e de fácil compreensão. ${ }^{26}$

À exceção dos dicionários gerais, há também os glossários bilíngues, cujas entradas são classificadas de acordo com os temas específicos, tal como a série de minidicionários com temas específicos (inglês - chinês - uma outra língua estrangeira) pela Beijing Language and Culture University Press. Esta série de dicionários inclui as seguintes línguas estrangeiras (com exceção do inglês): coreano, vietnamita, alemão, japonês, italiano, português, espanhol, russo, árabe e francês. ${ }^{27}$

Pelo que se observa acima, apesar de existir uma diversidade de materiais que possam ajudar a formação em duas línguas estrangeiras, a distribuição entre línguas estrangeiras não está muito bem equilibrada; ou seja, para algumas línguas estrangeiras, existem mais materiais, e para outras, existem poucos. Diante desta situação, os professores, além de consultar os materiais existentes no mercado chinês, podem também consultar os materiais relevantes e publicados em outros países.

\section{(3). O ambiente de línguas e o modelo de formação:}

De acordo com Huang (2017:79), as instituições chinesas onde se oferece a formação em duas línguas estrangeiras devem estabelecer e fortalecer a relação com as instituições estrangeiras, incentivando os alunos a frequentar cursos em universidades estrangeiras. Apesar do mérito da sua proposta, não acreditamos que isto seja viável, visto que para garantir o resultado esperado do ensino de duas línguas estrangeiras, faz-se necessário organizar um número maior de horas/aula.

Isto quer dizer que os alunos inscritos nesta licenciatura, muitas vezes, não têm tempo suficiente para fazer intercâmbio em outras universidades estrangeiras, visto que eles precisam, primeiro, aprender bem as duas línguas, para depois ir com mais confiança ao estrangeiro, ajustando-se rapidamente ao estudo e vida que enfrentariam no estrangeiro. Embora o ambiente de língua seja importante, antes que os alunos façam intercâmbios no estrangeiro, convém que tenham o domínio das duas línguas. Dada a dificuldade de um bom domínio de duas línguas estrangeiras só com três ou quatro anos de aprendizado, não achamos viável fazer intercâmbio no estrangeiro para os alunos de licenciatura em duas línguas estrangeiras.

(4). A escolha dos alunos para a formação em duas línguas estrangeiras: Na opinião de Huang (2017:79), a formação em duas línguas estrangeiras exige 
muito dos alunos, por isso, quando os admitem, as universidades, geralmente, costumam considerar se os alunos são capazes de tolerar a tarefa pesada de estudar duas línguas estrangeiras ao mesmo tempo. Huang (2017:79) aponta as seguintes características nos alunos, que são valorizadas pelas universidades: a. forte disciplina e assiduidade no estudo; b. forte motivação para o estudo; c. forte apetência pelo conhecimento; d. o gosto por línguas estrangeiras. Pela nossa observação, são qualidades importantes. O processo de avaliação destas qualidades muitas vezes é realizado através da entrevista. Por meio de diálogo prévio com os alunos candidatos, as universidades tentam reconhecer estas qualidades nesses alunos.

\section{A proposta da disciplina de tradução inglês-português para os alunos de licenciatura:}

Nesta parte, pretendemos analisar a viabilidade da proposta da disciplina de tradução inglês - português para licenciandos do curso de português. Concretamente, iremos realizar a nossa análise a partir dos seguintes aspetos:

1. a situação atual do ensino de português na China;

2. as disciplinas principais na licenciatura do curso de língua portuguesa;

3. a necessidade da proposta de disciplina de tradução inglês - português

4. a viabilidade da proposta de disciplina de tradução inglês - português

\subsection{A situação do ensino de português na China:}

Nos últimos anos, tem havido cada vez mais instituições chinesas (até ao ano de 2018, havia 41 instituições ${ }^{28}$ ) a oferecer cursos de língua portuguesa (licenciatura em português ou disciplina de português para os alunos de inglês).

Apesar do aumento da quantidade de instituições chinesas a oferecer o curso de licenciatura nos últimos anos, as universidades onde se oferece o curso de mestrado de português ainda são escassas.

Na parte continental da China, só cinco universidades oferecem o curso de mestrado de português: a Universidade de Línguas Estrangeiras de Pequim, a Universidade de Estudos Internacionais de Xangai, a Universidade de Estudos Internacionais de Xi'an, a Universidade de Estudos Internacionais de Tianjin e a Universidade de Línguas Estrangeiras de Dalian.

Quanto à região de Macau, a Universidade de Macau, o Instituto Politécnico de Macau e a Universidade de Ciência e Tecnologia de Macau são as únicas três a oferecer o curso de mestrado de português. 
Por enquanto, há apenas duas universidades chinesas a oferecer o curso de doutoramento (ambas ficam na região de Macau), que são a Universidade de Macau e o Instituto Politécnico de Macau: a Universidade de Macau oferece o curso de Doutoramento em Estudos Literários e Culturais (português) e o de Doutoramento em Linguística Aplicada (português), ${ }^{29}$ e o Instituto Politécnico de Macau oferece o curso de Doutoramento em Português. ${ }^{30}$

$\mathrm{Na}$ China continental, para frequentar o curso de mestrado, os alunos, geralmente, têm que fazer quatro provas de admissão. Por exemplo, para o curso de mestrado de português ( 3 anos), os alunos devem fazer as seguintes provas:
a) A prova da língua portuguesa,
b) A prova de literatura e cultura dos países lusófonos (focando-se em Portugal e o Brasil) ou a prova de tradução entre o português e o chinês (conforme cada universidade),
c) A prova de língua segunda (geralmente é o inglês, também pode ser outras línguas estrangeiras),
d) A prova de política.

Geralmente, cada universidade admite somente dois ou três alunos por ano. Como previamente dito, na China continental, existem, no total, cinco universidades a oferecer o curso de mestrado de português, e cada ano somente doze ou treze alunos podem ser admitidos no curso de mestrado de português nessas universidades.

Tendo em conta a quantidade insuficiente de instituições chinesas a oferecer o curso de mestrado na China continental e a competitividade no ingresso do mestrado, muitos alunos que têm o plano de prosseguir o estudo de mestrado. Depois de acabar a licenciatura, decidem fazer o mestrado em Macau, Portugal ou o Brasil. Ademais, o mestrado em Macau (Portugal, o Brasil) tem uma duração de dois anos, o que também constitui um outro fator muito atrativo para os alunos chineses, uma vez que o mestrado de português na China continental dura três anos.

\subsection{As disciplinas principais na licenciatura da língua portuguesa:}

Como mencionamos, no presente trabalho, além de apresentar a situação de formação em duas línguas estrangeiras na China, também iremos realizar uma análise de viabilidade de disciplina de tradução inglês - português para os licenciandos chineses em português. Nesta parte, iremos apresentar as principais disciplinas da licenciatura em português na China continental, para que os leitores possam ter uma ideia sobre as práticas concretas do ensino de português nas instituições chinesas.

Para ajudar à compreensão dos leitores, iremos citar as unidades escolares pela Universidade de Estudos Internacionais de Xangai (uma das primeiras universidades chinesas a oferecer o curso de licenciatura de português, iniciado em 1978). Basicamente, os alunos da licenciatura de português devem frequentar as seguintes disciplinas de português ${ }^{31}$ : 


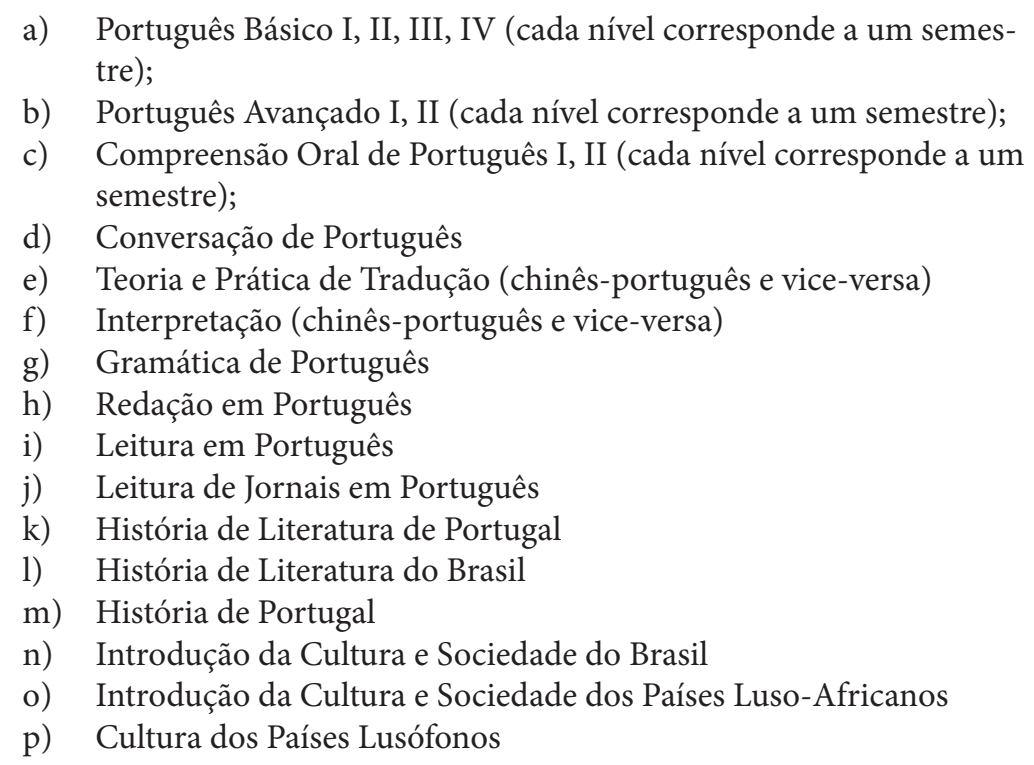

Pelo que se observa, existem duas disciplinas ligadas à tradução: a "Teoria e Prática de Tradução" e a "Interpretação". Como a interpretação não se enquadra no nosso escopo, iremos analisar aqui a disciplina "Teoria e Prática de Tradução".

Trata-se de uma disciplina essencial da licenciatura em português, que tem como objetivo deixar os alunos informados sobre as principais escolas e teorias tradutológicas e, ao mesmo tempo, ajudar os alunos a dominar os métodos mais frequentes na tradução entre o chinês e o português.

Esta disciplina possui ênfase nos exercícios tradutórios praticados pelos alunos. Com base nas explicações dos métodos tradutórios pelo professor, os alunos fazem exercícios; posteriormente, o professor faria comentários e explicaria as traduções feitas pelos alunos.

Quanto aos materiais didáticos, a obra "Tradução Português-Chinês: Teoria e Prática” (escrita por Yu Xiang (2011), doutor em Linguística pela Universidade de Aveiro e professor no Instituto Politécnico de Macau) é recomendada, assim como também se preparam materiais suplementares (os exercícios de tradução).

De fato, a organização da disciplina de "Teoria e Prática de Tradução (português - chinês e vice-versa)" pela Universidade de Estudos Internacionais de Xangai pode refletir a organização desta disciplina na maior parte das instituições chinesas onde se oferece a licenciatura em português (abordagem breve das teorias tradutológicas e ênfase nas práticas tradutórias).

$\mathrm{Na}$ realidade, esta organização está relacionada com as horas/aula distribuídas para esta disciplina, que, geralmente, são 72 horas curriculares (dois semestres); como os professores têm que explicar não só a tradução português - chinês, mas também a tradução chinês - português, não devem se ater na apresentação das escolas e teorias tradutológicas por um longo período. Isto significa dizer que as aulas de tradução para os licenciandos focam-se mais na prática do que nas teorias.

Com o objetivo de ilustrar melhor o que se afirma acima, podemos considerar os conteúdos de ensino para a disciplina "Teoria e Prática de Tradução (português 
- chinês e vice-versa)", que conta com um total de 72 horas curriculares (cada hora tem 45 minutos), cujos conteúdos lecionados dividem-se nos seguintes aspetos ${ }^{32}$ :

(1). Introdução breve às teorias tradutológicas (12 horas curriculares):

a) A definição, critério e classificação de tradução (3 horas curriculares)

b) História breve de tradução (2 horas curriculares)

c) O processo tradutório; a qualidade dos tradutores; como melhorar o nível de tradução (2 horas curriculares)

d) Traduzibilidade e limite na tradução; teoria comunicativa da tradução (2 horas curriculares)

e) Comparação sintática e lexical entre o português e o chinês (3 horas curriculares)

(2). Métodos concretos na tradução português - chinês (30 horas curriculares) incluindo: como resolver os problemas lexicais e gramaticais, omissão, acréscimo, transposição, como traduzir as orações subordinadas adjetivais e adverbiais, como traduzir o grau comparativo, e como traduzir as orações compridas.

(3). Métodos concretos na tradução chinês - português (30 horas curriculares) incluindo: tradução literal e tradução livre, omissão, acréscimo, transposição, como traduzir os adjetivos, como traduzir as construções típicas chinesas, como resolver os problemas lexicais e gramaticais, e como traduzir as orações longas.

Pela informação supracitada, pode notar-se que a ênfase fica sempre nas práticas concretas (as explicações dos métodos concretos na tradução português - chinês e vice-versa).

\subsection{A necessidade e viabilidade da disciplina de tradução inglês - outra língua estrangeira:}

Como referimos várias vezes acima, a maior parte dos alunos chineses estudam inglês na escola secundária e fazem prova de inglês no exame nacional de admissão à Universidade. Além do inglês, os alunos também podem escolher russo, francês, alemão, japonês e espanhol; no entanto, tendo em conta a influência do inglês como língua global e a qualificação dos professores de inglês, a esmagadora maioria dos alunos escolhem o inglês na escola secundária.

Os alunos que escolhem a licenciatura de línguas estrangeiras, geralmente, têm um nível intermediário de inglês (na escola secundária, os alunos chineses estudam toda a gramática do inglês), por isso, para os professores, torna-se muito importante ajudar os alunos a aproveitar os conhecimentos linguísticos do inglês para a aprendizagem da segunda língua estrangeira, evitando, ao mesmo tempo, a transferência negativa (para a "transferência negativa", iremos abordar abaixo) do inglês na aprendizagem desta segunda língua estrangeira.

Quanto à transferência linguística, Wang (2012:132) indica que se refere a um fenômeno em que os aprendentes tendem a (consciente ou subconscientemente) aplicar os conhecimentos das línguas dominadas (especialmente da língua 
materna) na aprendizagem de outras línguas, e o resultado pode ser positivo (transferência positiva) ou negativo (transferência negativa).

Conforme Li (2012:157), estas transferências linguísticas podem ser divididas em dois tipos: positive transfer (transferência positiva) e negative transfer (transferência negativa): pela transferência positiva, as semelhanças entre a língua materna (L1) e a língua segunda (L2) facilitam a aprendizagem da L2; pela transferência negativa, as diferenças entre a L1 e a L2 travam a aprendizagem da L2; ou seja, diante dos conhecimentos da L1 na aprendizagem da L2, vão surgir erros linguísticos. Resumindo as suas considerações, Li (2012:157) salienta que é muito frequente os aprendentes usarem os conhecimentos da L1 no estudo da L2 e isso pode ajudar ou levantar obstáculos na aprendizagem da L2.

Sobre isso, Wei \& Peng (2015:120) indicam que quanto mais próximas a L1 e a L2 são, maior a probabilidade de ocorrer o positive effect (efeito positivo) na aprendizagem da L2; e quanto menos próximas a L1 e a L2 são, maior a probabilidade de ocorrer o negative transfer (transferência negativa).

Além das transferências exercidas pela língua materna (L1) na aprendizagem da língua segunda (L2), a língua segunda (L2) também pode influenciar a aprendizagem da língua terceira (L3).

Ao comentarem o modelo de formação em duas línguas estrangeiras, Zhu \& Zhao (2010:14) apontam que este modelo é razoável e pode ser explicado com base nas considerações em relação à "língua terceira (L3)". Quanto à ideia de "língua terceira (L3)", Zhu \& Zhao (2010:14) citam as palavras de Jorda (2005), indicando que a "terceira língua (L3)" consiste numa ideia global, podendo ser uma ou mais línguas que os aprendentes estudam além da língua materna (L1) e da língua segunda (L2) dominada (embora o domínio possa não ser perfeito).

Sobre as possíveis transferências da língua segunda (L2) para a língua terceira (L3), de acordo com Cenoz (2001, citado por Zhu \& Zhao, 2010:14), a transferência da L2 sobre a L3 está relacionada com a distância linguística entre ambas as línguas: quanto mais próximas são as duas línguas, mais os aprendentes tendem a aplicar os conhecimentos da L2 na aprendizagem da L3. Leung (2005, citado por Zhu \& Zhao, 2010:14), através de investigação empírica, tira também uma conclusão semelhante: se a L2 é próxima da L3 tipologicamente, facilita-se a aprendizagem da L3.

De acordo com a nossa pesquisa, existem dois tipos de modelos que podemos considerar:

\section{(1). As explicações em inglês sobre os conteúdos linguísticos do português:}

$\mathrm{Na}$ Universidade de Línguas Estrangeiras de Pequim, para certas licenciaturas de línguas estrangeiras, devido à falta de professores chineses qualificados, nas primeiras edições, geralmente são os professores estrangeiros a dar aulas.

Como a única língua estrangeira que a maioria dos alunos sabem antes de entrar na universidade é o inglês, no primeiro ano da licenciatura (ou no primeiro semestre), os professores estrangeiros usam o inglês como uma língua transitória na explicação da outra língua estrangeira. Por exemplo, em 2008, a 
primeira edição da licenciatura de islandês foi aberta nesta universidade chinesa; no entanto, o único professor do quadro de docentes da universidade veio da Islândia, e, por isso, no início das aulas, o professor explicou os conhecimentos linguísticos do islandês por meio do inglês.

Para este modelo, os professores aproveitam o inglês como uma língua transitória a fim de dar explicações a respeito dos conhecimentos do islandês. No processo de aprendizagem, consciente ou subconscientemente, os alunos fazem análises comparativas e contrastivas entre o inglês e o islandês. Tendo em conta que é muito provável que algumas conclusões de comparação e contraste tiradas pelos alunos na aprendizagem não sejam corretas e generalizáveis, na nossa opinião, sugerimos a inclusão de disciplinas a serem ministradas pelos professores estrangeiros, que abordem a comparação e contraste entre as duas línguas em questão, ajudando os alunos a conhecer e sintetizar as semelhanças e diferenças entre duas línguas, ativando a transferência positiva e evitando a transferência negativa do inglês na aprendizagem de outra língua estrangeira.

(2). Os professores chineses de línguas estrangeiras (com exceção do inglês) dão aulas sobre a comparação e contraste entre o inglês e a outra língua estrangeira que eles ensinam:

Os professores de línguas estrangeiras (com exceção do inglês), como dominam bem os conhecimentos da sua própria área (uma língua estrangeira específica) e também já sabem o inglês, podem ser eles a dar aulas de comparação e contraste entre o inglês e a outra língua estrangeira aos alunos.

Quanto à nossa proposta, iremos adotar o segundo modelo, ou seja, deixar os professores chineses de línguas estrangeiras (com exceção do inglês) a dar aulas sobre a comparação e contraste entre o inglês e a outra língua estrangeira, que servirá como base para as aulas de tradução inglês - a outra língua estrangeira.

$\mathrm{Na}$ nossa consideração, os alunos da licenciatura em duas línguas estrangeiras, além de ter as aulas do inglês (lecionadas por professores de inglês) e as aulas de outra língua estrangeira B (lecionadas pelos professores da língua B), devem ter também as aulas de comparação e contraste entre o inglês e a língua B (nível I) e de tradução entre o inglês e a língua B (nível II) (lecionadas pelos professores da língua B). As aulas de comparação e contraste entre o inglês e a língua $B$ serviriam, neste caso, como base para as aulas de tradução entre o inglês e a língua B, por isso, designamos "nível I" e "nível II": o "nível I" para o primeiro semestre e o "nível II" para o segundo semestre.

\subsection{A viabilidade da disciplina de tradução inglês - português:}

Na parte de acima, abordamos o modelo que queríamos aplicar na nossa proposta, ou seja, que os alunos da licenciatura em duas línguas estrangeiras deveriam ter as seguintes disciplinas:

a. as disciplinas do inglês, que são lecionadas pelos professores de inglês; 
b. as aulas de outra língua estrangeira B, que são lecionadas pelos professores da língua B;

c. as aulas de comparação e contraste entre o inglês e a língua B e de tradução entre o inglês e a língua $B$, que também são lecionadas pelos professores da língua $\mathrm{B}$.

Nas instituições chinesas, por enquanto, para o ensino de português, ainda não existe a licenciatura em duas línguas estrangeiras (inglês e português); ou seja, os alunos precisam estudar bem o português e quando estes acabam o curso, podem usar esta língua para se inserir no mercado de trabalho.

Todos os licenciandos chineses devem estudar o inglês (a disciplina chama-se College English, que é para todos os licenciandos, com exceção dos licenciandos de inglês, só que as horas curriculares são em número muito menor: em cada semana há cerca de 4 horas curriculares (isso também pode variar conforme a instituição universitária). Com esta organização curricular, os alunos podem manter e aprofundar os conhecimentos do inglês adquiridos na escola secundária, apesar de não conseguirem dominar tão bem o idioma quanto os licenciandos em inglês.

De fato, elevar o nível do inglês não é o objetivo principal da nossa proposta; ou seja, os alunos abrangidos pela nossa proposta, de acordo com a nossa consideração, devem dominar relativamente bem o inglês. Dado isso, os alunos, antes de estudar a tradução inglês - português, precisam reforçar mais o seu nível de inglês quando da aprendizagem do português.

A disciplina de tradução inglês - português, conforme a nossa ideia e com base nas disciplinas tradicionais de tradução entre português e chinês, teria duração de um ano (dois semestres, com 2 horas curriculares por semana, totalizando 72 horas curriculares) e seria composta por duas partes:

d. explicações sobre as semelhanças e diferenças lexicais e sintáticas entre português e inglês, refletindo as considerações de comparação e contraste entre duas línguas (no primeiro semestre do terceiro ano da licenciatura: 36 horas curriculares no total e 2 horas curriculares por semana).

e. práticas de tradução inglês - português, devido às horas curriculares e tendo em conta o fato de que os alunos estudam inglês há muitos anos, nesta disciplina, a nossa atenção centra-se na tradução do inglês para o português (no segundo semestre do terceiro ano da licenciatura: 36 horas curriculares no total e 2 horas curriculares por semana).

Quanto à esta divisão de duas partes, a nosso ver, antes de os alunos começarem a dedicar-se aos exercícios de tradução inglês - português, convém que tenham conhecimento das diferenças e semelhanças entre as duas línguas (inglês e português); dado isso, a primeira parte da nossa disciplina mantém o foco nas explicações sobre as semelhanças e diferenças lexicais e sintáticas entre 
o português e o inglês, e a segunda parte da nossa disciplina volta-se para as práticas tradutivas do inglês para o português.

Esta disciplina, segundo a nossa consideração, seria ofertada a partir do terceiro ano da licenciatura, porque para os alunos de licenciatura de línguas estrangeiras (com exceção do inglês), geralmente, não são organizadas disciplinas relacionadas com o inglês no primeiro ano escolar. Concretamente, os licenciandos de português só começam a estudar inglês a partir do segundo ano da licenciatura. Mesmo que tenham um bom nível de conhecimento de inglês, depois de um ano sem aplicação prática, é muito provável que alguns alunos precisem recuperar os conhecimentos linguísticos esquecidos. Recomendase que os licenciandos de português estudem bem o inglês no segundo ano; só com isso é que no terceiro ano podem acompanhar a nossa disciplina proposta "tradução inglês - português".

Isto, por enquanto, ainda é uma hipótese por nós proposta e precisamos elaborar condições de implementação, as competências específicas a desenvolver e, por fim, pô-la em prática. Talvez seja possível que surjam obstáculos inesperados no nosso processo de concretização. Neste momento, pelo que sabemos, existem ainda alguns problemas por resolver, tais como os materiais e a qualificação dos professores.

Com relação aos materiais que possam ser utilizados na "tradução inglês português", no mercado chinês, até agora não existem muitos materiais para responder ao que percebemos serem as especificidades da nossa proposta. Os únicos materiais a que temos acesso são alguns dicionários bilíngues de bolso (português - inglês) ou glossários multilíngues (português - inglês - chinês). Talvez estes dicionários possam servir como uma base de referência no processo de aprendizagem pelos alunos, mas isso não nos afigura suficiente. Perante isso, os professores, ao prepararem as aulas, podem consultar os seguintes tipos de livros:

a. os livros publicados na China sobre a comparação e tradução entre o inglês e outras línguas estrangeiras (com exceção do português), apesar de isso envolver, muitas vezes, conhecimentos de uma terceira língua estrangeira pela parte dos professores (inglês, português, uma outra língua estrangeira); eles podem inspirar-se nestes livros para depois preparar as aulas;

b. os livros (escritos em inglês ou português) publicados em outros países, que abordam a comparação e tradução entre o inglês e o português;

c. os livros (escritos em inglês ou português) publicados em outros países, que embora não abordem a comparação e tradução entre o inglês e o português, oferecem conhecimentos interlinguísticos de forma indireta (tais como as gramáticas de português escritas em inglês e as gramáticas de inglês escritas em português; de fato, os dicionários bilíngues também devem ser classificados nestas categorias). 


\section{Notas conclusivas:}

Com o aumento das instituições chinesas que oferecem o curso de português, a competitividade torna-se cada vez mais intensa. Como ampliar a perspectiva de trabalho dos graduados e como formar os alunos para que eles se tornem talentos interdisciplinares tem sido um tema muito debatido.

No presente trabalho, centramo-nos no segundo tipo de formação interdisciplinar, que é a formação em duas línguas estrangeiras. Concretamente, realizamos uma apresentação detalhada sobre a formação em duas línguas estrangeiras nas instituições chinesas (no nível de licenciatura e no nível de mestrado; sendo o nosso foco neste trabalho no nível de licenciatura); propusemos, igualmente, uma hipótese de adotar uma disciplina de tradução inglês - português para os licenciandos de português nas instituições chinesas.

Nas licenciaturas tradicionais de línguas estrangeiras (com exceção da licenciatura de inglês), os alunos têm que, concentrar se na aprendizagem de uma nova língua estrangeira (por exemplo, os alunos da licenciatura de português têm que se concentrar na aprendizagem do português, que, para os alunos, é uma nova língua, já que a maioria dos alunos chineses estudam só inglês na escola secundária). No entanto, isso não quer dizer que estes alunos não tenham aulas de inglês; eles têm, porém, a ênfase nestas licenciaturas não está no ensino de inglês, mas no ensino desta nova língua estrangeira (por exemplo, os licenciandos de português também têm aulas de inglês, embora as horas curriculares sejam muito poucas, visto que a ênfase do ensino desta licenciatura se mantém no idioma português e não no inglês).

Nas licenciaturas em duas línguas estrangeiras (o inglês e uma outra língua estrangeira: língua B), a ênfase é colocada em ambas as línguas; as percentagens de horas curriculares destas duas línguas, embora sejam diferentes, não têm uma grande diferença entre si.

A formação da licenciatura em duas línguas estrangeiras, por enquanto, tem uma insuficiência: as duas línguas são ensinadas separadamente e não existem disciplinas que possam interligar os conhecimentos linguísticos entre as duas línguas.

Levando estas questões em consideração e com base na formação de licenciatura em português, propomos a criação da disciplina de tradução inglês - português, visando convergir os conhecimentos entre as duas línguas. Concretamente, esta disciplina, segundo a nossa consideração, é composta por duas partes: a. explicações sobre as semelhanças e diferenças lexicais e sintáticas entre inglês e português; b. práticas de tradução inglês - português (sendo as explicações de semelhanças e diferenças entre duas línguas a base das práticas tradutórias).

Como a criação da disciplina de tradução inglês - português ainda está na fase hipotética e exploratória, embora tenhamos levantado alguns problemas que possam vir a existir, é provável que ainda não nos tenhamos conscientizado sobre alguns fatores, que, a nosso ver, podem ser objeto de discussão e resposta em trabalhos futuros. 


\section{Notas}

1. Uma das universidades chinesas orientadas na área do ensino de línguas estrangeiras.

2. http://www.sjc.shisu.edu.cn/01/80/c62a384/page.htm, consultado no dia 8 de jul. de 2019.

3. A maioria dos alunos chineses, antes de frequentar a universidade, estuda inglês na escola secundária; além disso, os alunos também podem escolher russo, francês, alemão, espanhol ou japonês para a aprendizagem em vez do inglês. Os alunos só podem escolher uma língua estrangeira no exame vestibular.

4. Uma das universidades chinesas orientadas na área de ensino de línguas estrangeiras.

5. http://en.dlufl.edu.cn/jxky/zysz/2011-09-21/24087.htm, consultado no dia 31 de out. de 2019.

6. https://zsc.ynnu.edu.cn/info/1021/1442.htm, consultado no dia 31 de out. de 2019.

7. Quanto a estas duas instituições chinesas, iremos desenvolvê-las com mais detalhes abaixo.

8. A licenciatura de português pertence a esta categoria.

9. De acordo com a nossa pesquisa.

10. Nas instituições chinesas, há dois tipos de mestrados: o mestrado profissionalizante (com uma duração de 2 anos) e o mestrado acadêmico (com uma duração de 3 anos).

11. Uma das universidades chinesas orientadas no ensino de línguas estrangeiras.

12. http://en.dlufl.edu.cn/jxky/zysz/2009-12-16/14958.htm, consultado no dia 9 de jul. de 2019.

13. http://en.dlufl.edu.cn/jxky/zysz/2009-12-16/14961.htm, consultado no dia 9 de jul. de 2019.

14. http://en.dlufl.edu.cn/jxky/zysz/2009-12-16/14961.htm, consultado no dia 9 de jul. de 2019.

15. http://en.dlufl.edu.cn/jxky/zysz/2009-12-16/14962.htm, consultado no dia 9 de jul. de 2019.

16. http://en.dlufl.edu.cn/jxky/zysz/2009-12-16/14962.htm, consultado no dia 9 de jul. de 2019.

17. Uma das universidades chinesas orientadas na área de ensino de línguas estrangeiras.

18. https://gsti.bfsu.edu.cn/info/1130/1678.htm, consultado no dia 9 de jul. de 2019.

19. https://gsti.bfsu.edu.cn/info/1107/1104.htm, consultado no dia 9 de jul. de 2019.

20. https://gsti.bfsu.edu.cn/info/1107/1104.htm, consultado no dia 9 de jul. de 2019.

21. https://gsti.bfsu.edu.cn/info/1111/1976.htm, consultado no dia 9 de jul. de 2019.

22. Na visita aos países da Ásia Central (Turquemenistão, Cazaquistão, Uzbequistão, Quirguistão) em setembro de 2014, o Presidente Chinês Xi Jinpin propôs, pela primeira vez, a ideia da construção do "Cinturão Econômico da Rota da Seda" (http://theory.people.com.cn/n/2013/0913/c49150-22908144.html, consultado no dia 31 de out. de 2019); em outubro do mesmo ano, durante a visita dele para a ASEAN (Association of Southeast Asian Nations), sugeriu ele o conceito estratégico de construção da "Rota Marítima da Seda" do século XXI (http:// 
www.xinhuanet.com//world/2013-10/03/c_125482056.html, consultado no dia 31 de out. de 2019). As duas ideias dele consistem na base do planejamento da iniciativa chinesa de "Uma Faixa, Uma Rota" (a palavra "Faixa", às vezes, é substituída pela palavra "Cinturão"); através desta iniciativa, a China pretende desenvolver ativamente parcerias econômicas com países ao longo da "Faixa e Rota". Há, no total, além da China, 73 países envolvidos nesta iniciativa, que se distribuem, principalmente, na Ásia (a Europa de Leste, a Europa Central, a África, a América do Sul e a América Central) (Mahe Suti, 2019:41).

23. http://www.bfsu.edu.cn/overview, consultado no dia 9 de jul. de 2019.

24. De acordo com a estipulação pelo Ministério de Educação da China, os alunos começam a aprender o inglês aos 8 anos. http://old.moe.gov.cn//publicfiles/ business/htmlfiles/moe/moe_12/200502/5939.html, consultado no dia 10 de jul. de 2019.

25. As informações sobre os dicionários bilingues de bolso foram retiradas da Publisher's Note do Collins German Dictionary \& Grammar.

26. As informações sobre os dicionários bilingues com gramática foram retiradas da Publisher's Note do Collins German Dictionary \& Grammar.

27. http://www.blcup.com/PList?_content=\%E8\%AF\%8D\%E6\%B1\%87\%E5\%88\%86 \%E7\%B1\%BB\%E5\%AD\%A6\%E4\%B9\%A0\%E5\%B0\%8F\%E8\%AF\%8D\%E5\%85 $\%$ B8,consultado no dia 14 de jul. de 2019.

28. http://dy.163.com/v2/article/detail/DDH7V3Q60516AO7B.html, consultado no dia 11 de jul. de 2019.

29. https://fah.um.edu.mo/programmes-offered/, consultado no dia 11 de jul. de 2019.

30. http://www.ipm.edu.mo/languages/pt/phd_ptstudy_objective.php, consultado no dia 1 de nov. de 2019.

31. http://www.selas.shisu.edu.cn/195/list.htm, consultado no dia 11 de jul. de 2019.

32. http://cc.shisu.edu.cn/G2S/site/preview\#/rich/v/49590? currentoc=533, consultado no dia 12 de jul. de 2019.

\section{Referências}

Comitê Consultivo para Especialidades de Línguas Estrangeiras do Ensino Superior (1998:1-6). Opiniões sobre a Reforma do Ensino de Licenciatura em Línguas Estrangeiras para o Século XXI, Shanghai: Foreign Language World.

Gao, Weiwan \& Gai, Feihong (2011). French Grammar: Comparison between French and English, Higher Education Press.

Gu, Yongqing (2006). The Comparison and Translation between Japanese and English (Elementary Level), Henan People’s Publishing House.

Huang, Song (2017:78-79). Analysis on the Training Mode of Complex Foreign Language (English and Another Foreign Language) in Universities of Fujian Province under the Background of the Belt and Road Initiative, Changchun: Intelligence.

Li, Dongliang (1993). Grammar between German and English, Hubei Science \& Technology Press.

Li, Xiaoguang (2012:157-158). The Application of Language Transfer Theory in English Writing Teaching, Taiyuan: Journal of Taiyuan Urban Vocational College. 
Ma, Dong \& Chen, Fengyan (2019:83-87). Reflections on the Training Mode of Complex Foreign Language Teaching - From the Perspective of the Initiative "One Belt, One Road", Harbin: Cognition and Practice.

Mou, Jia (2015:53-54). Study on the Complex Foreign Language Specialty Model of Xiangxi Tourist Area, Kaifeng: Journal of Kaifeng Institute of Education.

Mou, Jia (2015:164-165). Consideration on the Training Mode of "Complex Foreign Language" of Students of Tourism in Wuling Mountain Area, Chifeng: Journal of Chifeng University (Natural Science Edition).

Sun, Wei (2015:90-92). Research on the Training Mode of Complex Foreign Language, Lanzhou: Journal of Lanzhou Institute of Education.

Wang, Yingying (2012: 132-134). Effect of Language Transfer on College Students' Writing, Harbin: Foreign Language Research.

Wei, Yali \& Peng, Jinding (2015: 119-125). Research in Language Transfer in Third-Language Acquisition, Urumqi: Journal of Xinjiang Normal University (Philosophy and Social Sciences).

Yu, Xiang (2011). Tradução Português - Chinês: Teoria e Prática, Foreign Language Teaching and Research Press.

Zhu, Xiaohui \& Zhao, Zhongde (2010:14-18). Training of Bi-foreign Languages Majors - Research Based on Feedback Survey, Dalian: Foreign Languages and Their Teaching.

Recebido em: 28/07/2019

Aceito em: 03/10/2019 